\title{
Horizontal respect distance for hydraulic fracturing in the vicinity of existing faults in deep geological reservoirs: a review and modelling study
}

\author{
Rachel F. Westwood $(\mathbb{D} \cdot$ Samuel M. Toon $\mathbb{D} \cdot$ Peter Styles $\mathbb{D} \cdot$ Nigel J. Cassidy
}

Received: 28 February 2017 / Accepted: 12 June 2017 / Published online: 28 June 2017

(C) The Author(s) 2017. This article is an open access publication

\begin{abstract}
Hydraulic fracturing is widely used in the petroleum industry to enhance oil and gas production, especially for the extraction of shale gas from unconventional reservoirs. A good understanding of the vertical distance which should be preserved between hydraulic stimulation and overlying aquifers (potable water) has been demonstrated as being greater than $600 \mathrm{~m}$ (2000 feet). However, the effective application of this technique depends on many factors; one of particular importance is the influence of the fracturing process on pre-existing fractures and faults in the reservoir, which,
\end{abstract}

R. F. Westwood $(\bowtie) \cdot$ S. M. Toon · P. Styles ·

N. J. Cassidy

School of Geography, Geology and the Environment,

Keele University, Keele, Staffordshire ST5 5BG, UK

e-mail: r.f.westwood@keele.ac.uk

S. M. Toon

e-mail: s.m.toon@keele.ac.uk

P. Styles

e-mail: p.styles@keele.ac.uk

N. J. Cassidy

e-mail: n.j.cassidy@bham.ac.uk

Present Address:

R. F. Westwood

Learning and Professional Development Centre, 59/60 The

Covert, Keele University, Keele, Staffordshire ST5 5BG, UK

Present Address:

N. J. Cassidy

School of Engineering, University of Birmingham, Edgbaston, Birmingham B15 2TT, UK however, to date, has had little analysis. Specifically, the identification of the required respect distance which must be maintained between the hydraulic fracturing location and pre-existing faults is of paramount importance in minimizing the risk of felt, induced seismicity. This must be an important consideration for setting the guidelines for operational procedures by legislative authorities. We investigate the respect distance using a Monte Carlo approach, generating fifty discrete fracture networks for each of three fracture intensities, on which a hydraulic fracturing simulation is run, using FracMan ${ }^{\circledR}$. The Coulomb stress change of the rock surrounding the simulated injection stage is calculated for three weighted source mechanisms combining inflation, strike-slip and reverse. The lateral respect distance is obtained using values from literature of the amount of stress required to induce movement on a pre-existing fault. We find that the lateral respect distance is dependent on fracture intensity and the failure threshold. However, the weighting of the source mechanism has limited effect on the lateral respect distance.

Keywords Hydraulic fracturing - Numerical modelling · Fault proximity $\cdot$ Stress $\cdot$ Shale gas · Fracture network

\section{Introduction}

Over the last decade, the development of shale gas, shale oil and shale liquids has transformed the energy 
industry, especially in the USA and Canada, where the shale industry is worth billions of dollars. However, there is still considerable debate over the risks associated with the extraction and exploitation of shale gas and oil, be they real or perceived. One of the key risks and operational concerns is felt seismicity and the requirement to mitigate this as much as possible by not reactivating pre-existing faults. This requires knowledge of the location of these faults and how far away, both laterally and vertically, hydraulic fracturing should occur in order not to reactivate the fault.

Exploitation and extraction of shale gas and oil has involved millions of hydraulic stimulations (commonly known as fracks). The process of hydraulic fracturing, through the injection of high-pressure water, along with sand or synthetic ceramic proppants and a small component of other chemicals $(<0.5 \%$ generally), intentionally stimulates new fracture growth, generating a connected fracture network and increasing permeability. The process induces a multitude of microseismic events (very small-scale earthquakes), which are routinely monitored from instrumented boreholes and a densely distributed network of surface sensors. This allows the location of fracturing to be identified and provides a means of tracking the efficiency, and the spatial and temporal progress of the hydraulic fracturing. These events normally have magnitudes below zero (Maxwell 2013; Verdon et al. 2010); however, since 2011, there have been several recorded examples of seismicity at magnitudes greater than 2.0 (Holland 2013), of which three (BC Oil and Gas Commission 2012; Clarke et al. 2014; Schultz et al. 2015) were felt and reported by local populations. In at least one of these cases (Clarke et al. 2014), hydraulic fracturing has influenced a preexisting fault causing it to slip to a sufficient extent and length to produce a felt earthquake. This has raised concerns with regulators, operators and the general public. Given the number of fracks performed over the last decade, statistically this is a very rare occurrence. However, the fact that it has occurred, demands that we attempt to understand the processes and situations which might lead to such an event.

Felt seismicity occurring near Blackpool, Lancashire, UK (Clarke et al. 2014), was associated with the first fracked well for shale gas in the UK, commencing just before and during the second stage of hydraulic fracturing and, as such, has become of considerable interest to all parties in the shale gas debate. Analysis of the seismicity shows that these felt events were caused by fluid injection reactivating preexisting faults (Clarke et al. 2014).

It is critically important to attempt to understand how the process of hydraulic fracturing might precipitate minor movements on faults, whether by the direct injection of fluid (Rutqvist et al. 2013, 2015) or by changing the ambient stress system sufficiently to overcome friction/mechanical impeding forces.

To our knowledge no attempt has been made to address the distance at which potential faults could be activated. The purpose of this paper is to investigate, using geomechanical modelling and Coulomb failure analysis, the magnitude of stress changes caused by hydraulic fracturing operations and the potential influence this might have on pre-existing structures. This paper investigates the respect distance from a fault for three different fracture intensities and weighted source contributions, using a combination of geomechanical modelling in FracMan ${ }^{\circledR}$ and Coulomb failure analysis in MATLAB $^{\circledR}$, with input parameters taken from real-world operational data, including injection volumes, pressure and pump time.

\section{Induced seismicity from hydraulic fracturing for shale gas}

In Oklahoma in the USA, an area where wastewater injection has been known to cause seismicity (Ellsworth 2013; Keranen et al. 2013, 2014; McGarr et al. 2015), a series of earthquakes, sixteen greater than Mw 2.0 and the largest at ML 2.9, were correlated to hydraulic fracturing treatment (Holland 2013). In Ohio, USA, another area where deep well fluid injection has caused seismicity (Kim 2013), hydraulic fracturing operations in at least two separate areas have caused events including a Mw 2.2 (Friberg et al. 2014) and a ML 3.0 (Skoumal et al. 2015). The first documented account of felt seismicity from hydraulic fracturing for shale gas in Europe was near Blackpool, UK (Clarke et al. 2014; Eisner et al. 2013) and included a ML 2.3 event. Of these examples three were felt: Blackpool, Ohio and Oklahoma.

However, in Canada hydraulic fracturing has triggered larger felt events. At the Horn River Basin, hydraulic fracturing in the proximity of pre-existing faults caused a series of events, with 21 greater than 
Mw 3.0 (BC Oil and Gas Commission 2012) after some 8000 hydraulic stimulations had already taken place. Schultz et al. (2015) report a sequence of 160 earthquakes with magnitudes ranging from $\mathrm{Mw} 1.7$ to 3.9 from the region of Crooked Lake, Alberta, which they correlate spatially and temporally with nearby hydraulic fracturing operations. Earthquakes of size ML 4.0 and 4.2 were reported near Fort St John in British Columbia (Atkinson et al. 2015a) and near Fox Creek, Alberta, dozens of events have been observed with the largest measuring M 4.4 (Atkinson et al. 2015b). At Doe-Dawson, in the Lower Montney, the same shale play as the events near Fort St John, at least six felt events have occurred (BC Oil and Gas Commission 2014).

\section{Faults and fracture networks}

Faults are rarely a single failure surface and usually consist of a region, throughout which numerous discontinuities branch, splay and rejoin. They usually have a broad range of lengths and throws which can be seen on a large-scale and on deep seismic reflection images as a single entity. However, on closer inspection, for example in an open-cut mine where the whole scale is visible (Fig. 1), they have a fractal distribution with discontinuities present down to scales of a few $\mathrm{cm}$ and possibly even smaller. An example is shown in the detailed mapping of faults visible from coal mine workings in the East Pennine coalfield (Bailey et al. 2005). This means that the influence of anthropogenic activities may stimulate movement even when the activity is some distance from the 'seismically imageable' position.

Modelling of injection-induced fault activation based on the Marcellus Shale, conducted by Rutqvist et al. (2013, 2015), found that shear failure occurred simultaneously with tensile failure and that hydraulic fracturing stimulation on its own may only produce small microseismic events. However, when a fault is present, the events are larger. They showed that for a critically stressed, permeable fault, the total length of shear rupture can be up to $200 \mathrm{~m}$ and moment magnitudes ranged from -2.5 to 0.5 .

Zoback and Gorelick (2012) have analysed the relationship between magnitude and fault size (Fig. 2) constrained by slip length. For the size of events which have been reported from hydraulic fracturing for shale

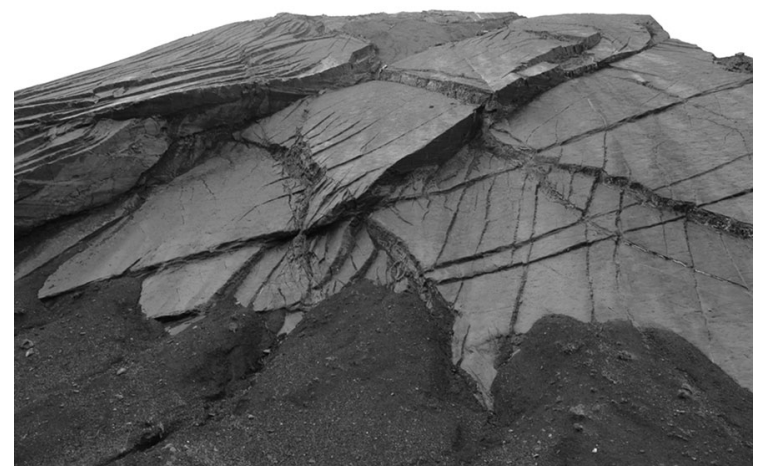

Fig. 1 Spire Slack open-cut coal mine. Coal face at Spire Slack open-cut coal mine, showing the fracture and fault networks down to a few $\mathrm{cm}$. The exposed face is approximately $50 \mathrm{~m}$ high

gas, it is likely that these faults have rupture lengths of less than a few hundred metres, with slips of the order of only a few millimetres to a few centimetres. These will be complex zones of faulting rather than individual faults.

Once hydraulic fracturing has been initiated, the fractures propagate perpendicular to the direction of the minimum stress and parallel to the direction of maximum stress. At depths of over $1000 \mathrm{~m}$, the depths at which hydraulic fracturing for shale gas occurs, this is generally vertical, with fractures propagating upward but deviating to horizontal for very shallow depths where lithostatic load is not the maximum stress component. Two studies (Davies et al. 2012; Flewelling et al. 2013), use data from thousands of

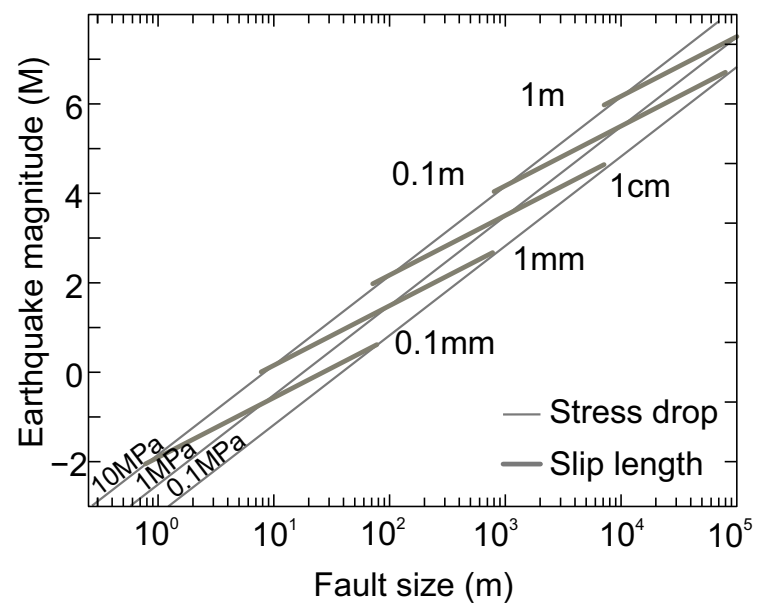

Fig. 2 Relationship between magnitude and fault size (length) plus various scaling parameters for earthquakes. Earthquake stress drops generally range between 0.1 and $10 \mathrm{MPa}$. (Modified from Zoback and Gorelick 2012) 
stimulations to show that the maximum vertical extent of hydraulic fracture propagation is, and all microseismicity occurs, less than $600 \mathrm{~m}$ vertically from the well perforation.

Horizontally, fractures will propagate in the direction of the maximum stress, opening against the smallest (minimum) stress. To our knowledge, no systematic study, similar to that of Davies et al. (2012) or Flewelling et al. (2013), has been carried out to examine the lateral distance at which seismicity could occur. However, seismicity at the Poland Township in Ohio occurred up to $850 \mathrm{~m}$ away from the well (Skoumal et al. 2015). Data analysis concluded that the hydraulic fracturing reactivated a pre-existing fault; although, it is not clear if this was due to direct injection into the fault or an alternative source of reactivation. These studies only considered microseismic event clouds and do not examine seismicity occurring as a result of changes to the stress field further afield from Coulomb stress.

Coulomb stress modelling has been used extensively to study failure in the context of earthquakes (Stein 1999; Kilb et al. 2002; Lin and Stein 2004; Toda et al. 2011; Sumy et al. 2014). However, limited work has been carried out to examine the Coulomb stress changes related to hydraulic fracturing. Vasudevan and Eaton (2011) demonstrate the technique by modelling the Coulomb stress change from the first 100 microseismic events, with magnitudes between -1 and -3 , occurring during hydraulic fracturing in Alberta, Canada. However, their source mechanisms were based on a simplistic model, without inflation.

\section{The shale reservoir model}

A two-stage discrete fracture network (DFN) and Coulomb stress model is used to calculate the stresses originating from each stage of a hydraulic fracturing process and the effect this has on any critically stressed faults in the vicinity. It is acknowledged that poroelastic contribution will also have an impact on the stress field, however, many argue that this is a 2 nd or 3rd order effect. This work focuses purely on the Coulomb stress change, with poro-elastic contributions being planned to add to further work.

The model represents a shale gas reservoir within a strike-slip faulting environment. The stresses are similar to those published for the Bowland and
Worston Shale Groups in the North West of England (de Pater and Baisch 2011). These formations lie at a depth of between 1957 and 2690 m, with an approximately $60 \mathrm{~m}$ thick layer of limestone separating the two groups. A horizontal well is defined in the top shale group with a single stimulation stage at a depth of $2220 \mathrm{~m}$ (Fig. 3).

The DFN was generated using the fracture modelling software FracMan ${ }^{\circledR}$ (Golder Associates (UK) Ltd 2015) by Golder Associates. The parameters of the DFN are provided in Table 1. The model was discretized over a $1 \mathrm{~km}$ cube, extending vertically from -1800 to $-2800 \mathrm{~m}$, bounding the shales at the top and bottom. The cube is layered vertically following the stratigraphy in Fig. 3. The elastic properties for each rock type are homogeneous across the layer and are provided in Table 2.

The stress regime is defined to be strike-slip. This means that the maximum and minimum compressive stresses, $\sigma_{1}$ and $\sigma_{3}$, are in the horizontal direction and the intermediate stress, $\sigma_{2}$, lies in the vertical direction. Hence, the maximum and minimum compressive horizontal stresses, $\sigma_{H}$ and $\sigma_{h}$ respectively, and the vertical stress, $\sigma_{v}$, are $\sigma_{H}>\sigma_{v}>\sigma_{h}$. We use a vertical stress gradient of $23,530 \mathrm{~Pa} / \mathrm{m}$, based on the calculations of Baisch and Vorös (2011), which at $2220 \mathrm{~m}$, gives $\sigma_{v}=52.24 \mathrm{MPa}$. The fracture closure pressure (FCP) can be used as a means of constraining the lower

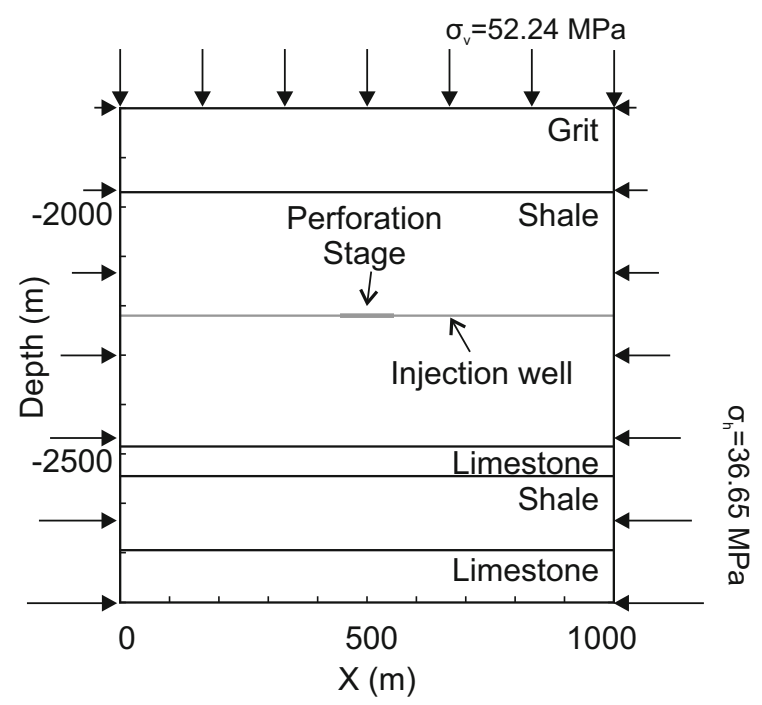

Fig. 3 A 2D-view of the layers, stresses and the well geometry used for modelling the $3 \mathrm{D}$ discrete fracture network. The maximum horizontal stress is perpendicular to the page, $\sigma_{H}=61.27 \mathrm{MPa}$ 
bound of the minimum horizontal stress gradient and the instantaneous shut in pressure (ISIP) can be used as an upper bound. These values vary with depth and for the Bowland Basin are in the range of 0.69-0.78 psi/ feet (15,608-17,644 Pa/m) (de Pater and Baisch 2011; Harper 2011; GMI Geomechanics Services 2011). Based on this range, we use $\sigma_{h}=36.65 \mathrm{MPa}$ and define the maximum horizontal stress as $\sigma_{H}=61.27 \mathrm{MPa}$.

The Young's modulus, $\mathrm{E}=42.5 \times 10^{9} \mathrm{~Pa}$, was calculated from the bulk and shear moduli provided in Harper (2011). The result is slightly higher than the static Young's Modulus values for some of the gasbearing shale plays in North America: Marcellus Shale 15.5 GPa (Dusseault 2013), Horn River 18-31 GPa (Dusseault 2013), but falls in the range of 20-80 GPa for the Barnett Shale (Agarwal et al. 2012; Dusseault 2013; Gale et al. 2007). The Poisson's ratio is defined as 0.25 , which is comparable to the Barnett Shale play (Dusseault 2013).

Natural fracture intensity can affect the distance and density of the resulting network of natural and hydraulic fractures. Fracture abundance (or intensity) is defined using a P32 measure type (fracture area/ volume). Three intensities within the top shale layer were considered: $0.15,0.25$ and 0.35 , with the natural fracture networks in the other layers remaining unchanged (Fig. 4). A Monte Carlo approach is taken whereby, for each P32 value, 50 random natural fracture sets are generated, each using the parameters given in Table 1.

A hydraulic fracture simulation is performed on each of the natural fracture sets. FracMan ${ }^{\circledR}$ uses the theory of critical stress analysis to perform the hydraulic fracturing simulation, maintaining a balance between the pumped fluid and the expanded volume of natural fractures and the new hydro-fracture. Induced tensile fractures develop from the well, which have a normal parallel to the direction of the minimum stress and intersecting fractures are pumped if they are dilatable. The constitutive equation, which relates the volume of fractures to the elastic properties of the rock, regional stresses and the internal fracture pore pressure, is solved in time steps. For further
Table 1 The properties used for creating the discrete fracture network

\begin{tabular}{ll}
\hline DFN parameters & \\
\hline Enhanced Baecher model & \\
Fracture size & Power law distribution \\
Aperture & $10^{-8} \mathrm{~m}$ \\
Permeability & $0.001 \mathrm{md}$ \\
Compressibility & $10^{-6} \mathrm{~Pa}^{-1}$ \\
Fracture orientation: distribution & Fisher \\
Fracture orientation: mean pole trend & 80 \\
Fracture orientation: mean pole plunge & 0 \\
\hline
\end{tabular}

Table 2 Rock characteristics for the model

\begin{tabular}{|c|c|c|c|c|}
\hline Parameters & Shale & Limestone $^{\mathrm{e}}$ & Grit & Fractures \\
\hline Young's modulus $(\mathrm{GPa})^{\mathrm{a}, \mathrm{d}}$ & 42.5 & 70.0 & 22.6 & \\
\hline Shear modulus $(\mathrm{GPa})^{\mathrm{b}}$ & 17.0 & 15.0 & & \\
\hline Bulk modulus $(\mathrm{GPa})^{\mathrm{b}}$ & 28.3 & 36.5 & & \\
\hline Poisson's ratio ${ }^{\mathrm{b}}$ & 0.25 & 0.22 & & \\
\hline Pore pressure $(\mathrm{Pa} / \mathrm{m})^{\mathrm{a}, \mathrm{b}}$ & & & & 10,200 \\
\hline Coefficient of friction ${ }^{a}$ & & & & 0.47 \\
\hline Friction angle $\left(^{\circ}\right)$ & & & & 25.17 \\
\hline Cohesion $(\mathrm{Pa})^{\mathrm{c}}$ & & & & 50,000 \\
\hline
\end{tabular}

Data from ${ }^{\mathrm{a}}$ Baisch and Vorös (2011) for shale and fractures, ${ }^{\mathrm{b}}$ Harper (2011) for shale and fractures, ${ }^{\mathrm{c}}$ Hoek (2007) for shale and fractures, ${ }^{\mathrm{d}}$ Hawkins and McConnell (1992) for grit. ${ }^{\mathrm{e}}$ Data for limestone from Henderson and Henderson (2009) 
information on the equations and processes used within FracMan ${ }^{\circledR}$, see Golder Associates (UK) Ltd (2015).

Water is pumped at a rate of approximately $7000 \mathrm{l} /$ $\min (1850 \mathrm{gal} / \mathrm{min})$ for $2 \mathrm{~h}$, with a total volume of approximately 840,000 l (221,900 gal) injected during the simulation. Differential pressure (the pressure difference between pore pressure and normal pressure on the fractures) at injection is set to $0.4 \mathrm{MPa}$. Hydraulic fracture growth is generated through new tensile fractures.

\section{Coulomb stress failure}

The Coulomb failure criterion is commonly used to identify failure in soil and rock mechanics (Jaeger 1972; Brady and Brown 1993; King et al. 1994).
Coulomb stress change (also known as the Coulomb failure function or Coulomb's Law), $\Delta \sigma_{f}$, in its simplest form is defined as

$\Delta \sigma_{f}=\Delta \tau+\mu\left(\Delta \sigma_{n}+\Delta P\right)$,

where $\Delta \tau$ is the shear stress change on the failure plane, $\Delta \sigma_{n}$, is the normal stress change, $\Delta P$, is the change in pore pressure and $\mu$ is the friction coefficient in the range $0-1$. When $\Delta \sigma_{f}$, exceeds a critical value, failure occurs; both increased shear and unclamping of faults can lead to failure.

The amount of change of stress required to trigger a fault has wide ranging values in the literature. Stein (1999) states that off-fault stress increases are rarely more than 0.1 MPa. Freed (2005) found that stress changes linked to aftershock triggering were in the region of 0.1-0.3 MPa. Kilb et al. (2002) increase the range stating that triggering thresholds of Coulomb
Fig. 4 Examples of the DFN for three P32 fracture intensities within the top shale layer and the resultant connected hydraulic and natural fractures

$$
\text { Fracture Intensity }=0.15
$$

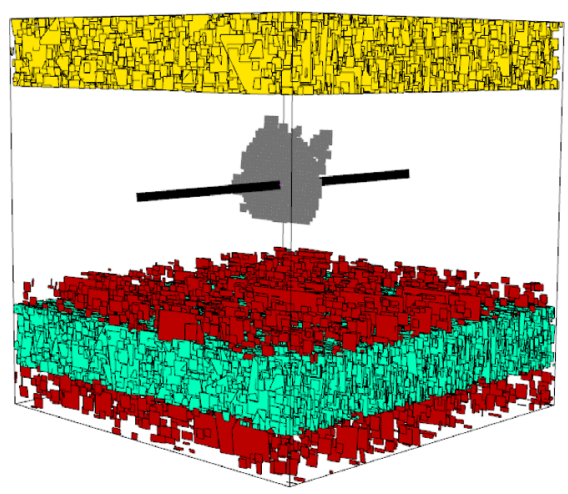

Fracture Intensity $=0.35$

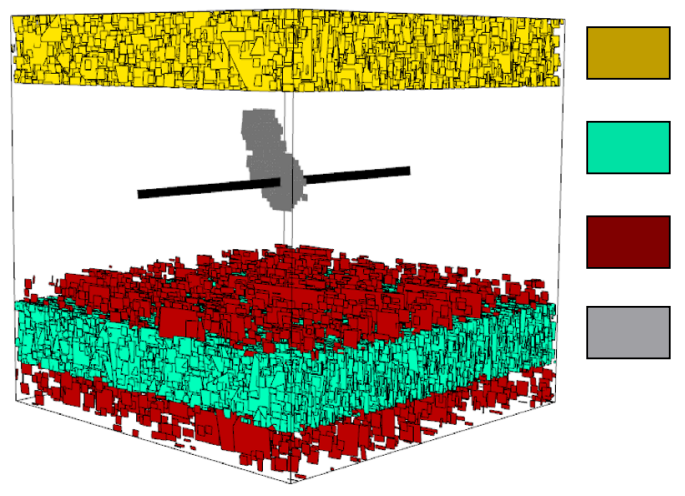

\section{Fracture Intensity $=0.25$}

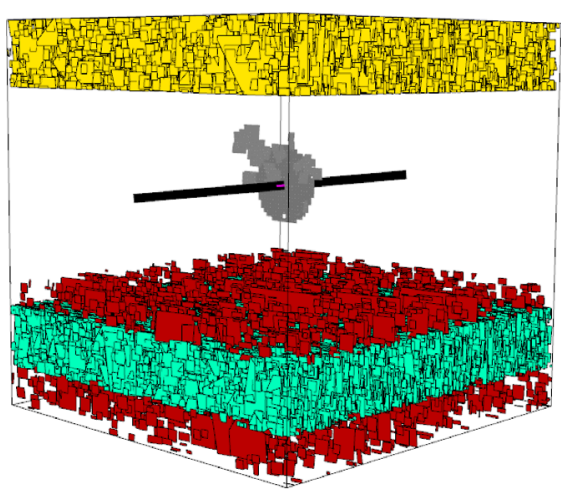

Grit

Shale

Limestone

Connected hydraulic and natural fractures 
Table 3 Average values over 50 simulations, per P32 fracture intensity value, of hydraulically fracturing the discrete fracture network

\begin{tabular}{llll}
\hline $\begin{array}{l}\text { Fracture } \\
\text { intensity }\end{array}$ & $\begin{array}{l}\text { Volume received by hydraulic fracture } \\
\left(\mathrm{m}^{3}\right)\end{array}$ & $\begin{array}{l}\text { Maximum flow distance in all fractures } \\
(\mathrm{m})\end{array}$ & $\begin{array}{l}\text { Total number of injected } \\
\text { fractures }\end{array}$ \\
\hline 0.15 & 709.57 & 364 & 1013.5 \\
0.25 & 255.64 & 428 & 867 \\
0.35 & 239.45 & 328.6 & 934 \\
\hline
\end{tabular}

failure stress are between 0.001 and $0.5 \mathrm{MPa}$, with the optimal value agreeing with Stein and Freed's lower bound of 0.1 MPa. Shapiro et al. (2006) agrees more with Stein (1999) providing a range of $0.001-0.1 \mathrm{MPa}$. The reported large variation in the triggering threshold may be influenced by several factors including, the fault geometry (kinks and bends in the fault plane would require a larger triggering stress to induce movement), fault orientation relative to the regional stress field, and differences in the coefficient of friction, as well as other fault properties.

The Coulomb stress failure was computed using the algorithms detailed by Okada (1992). Three weighted source contributions are investigated:

- $50 \%$ inflation, $25 \%$ strike-slip, $25 \%$ reverse;

- $25 \%$ inflation, $50 \%$ strike-slip, $25 \%$ reverse;

- $25 \%$ inflation, $25 \%$ strike-slip, $50 \%$ reverse.

For each simulation, we calculated failure on optimally orientated strike-slip faults at fixed intervals between depths of 1.5 and $3.5 \mathrm{~km}$. The respective maximum and minimum stress over depth is subsequently obtained for each $\mathrm{x}-\mathrm{y}$ point.

\section{Results}

Fifty fracture sets were generated for each P32 value and for the three source mechanism weightings. The average volume of fluid received by the initial hydraulic fracture is nearly three times more than the average values for the 0.25 and 0.35 fracture intensities (Table 3). However, the average maximum flow distance and average total number of injected fractures for 0.25 and 0.35 are within $15 \%$ of the average value for 0.15 .

An example of the stress maps for one of the fracture sets is given in Fig. 5. The Coulomb stress was calculated every $50 \mathrm{~m}$ laterally and vertically between depths of 1.5 and $2.5 \mathrm{~km}$ to generate a $4 \mathrm{~km}$ square maximum stress map.

The radiation pattern of the stress is similar for each intensity, with the trend of positive Coulomb stress failure occurring in the direction of the maximum horizontal stress. These areas, highlighted in the figure with solid contour lines, are places where failure may occur, depending on the amount of stress required to trigger an event.

Each of the stress maps for the fifty simulations are qualitatively similar (Fig. 6). Visually, using the stress maps, it appears that the lateral distance calculated from the simulation for each of the 50 fracture set realisations is close. However, quantitatively the results have a large range (Fig. 7). This is especially true for the $0.001 \mathrm{MPa}$ threshold where the largest range is over $200 \mathrm{~m}$. This variation is possibly due to the differences in orientation and interconnectivity of the natural fracture networks.

The lateral respect distance is obtained using the relationship between the maximum Coulomb stress and distance (Fig. 8). The maximum Coulomb stress over all depths decreases with distance and obeys a cubic law. Four stress threshold values (shown in Fig. 8 by a horizontal line), based on values in the literature, are used to obtain the respect distance:

- $0.5 \mathrm{MPa}$ (Kilb et al. (2002) upper bound)

- $\quad 0.3 \mathrm{MPa}$ (Freed (2005) upper bound)

- $0.1 \mathrm{MPa}$ (Stein (1999)/Freed (2005) lower bound/ Shapiro et al. (2006) upper bound/Kilb et al. (2002) optimal value)

- $0.001 \mathrm{MPa}$ (Shapiro et al. (2006) lower bound/ Kilb et al. (2002) lower bound)

\section{Discussion}

The results of the modelling indicate that the lateral distance decreases with stress threshold, this is to be 


\section{Source mechanism weightings}
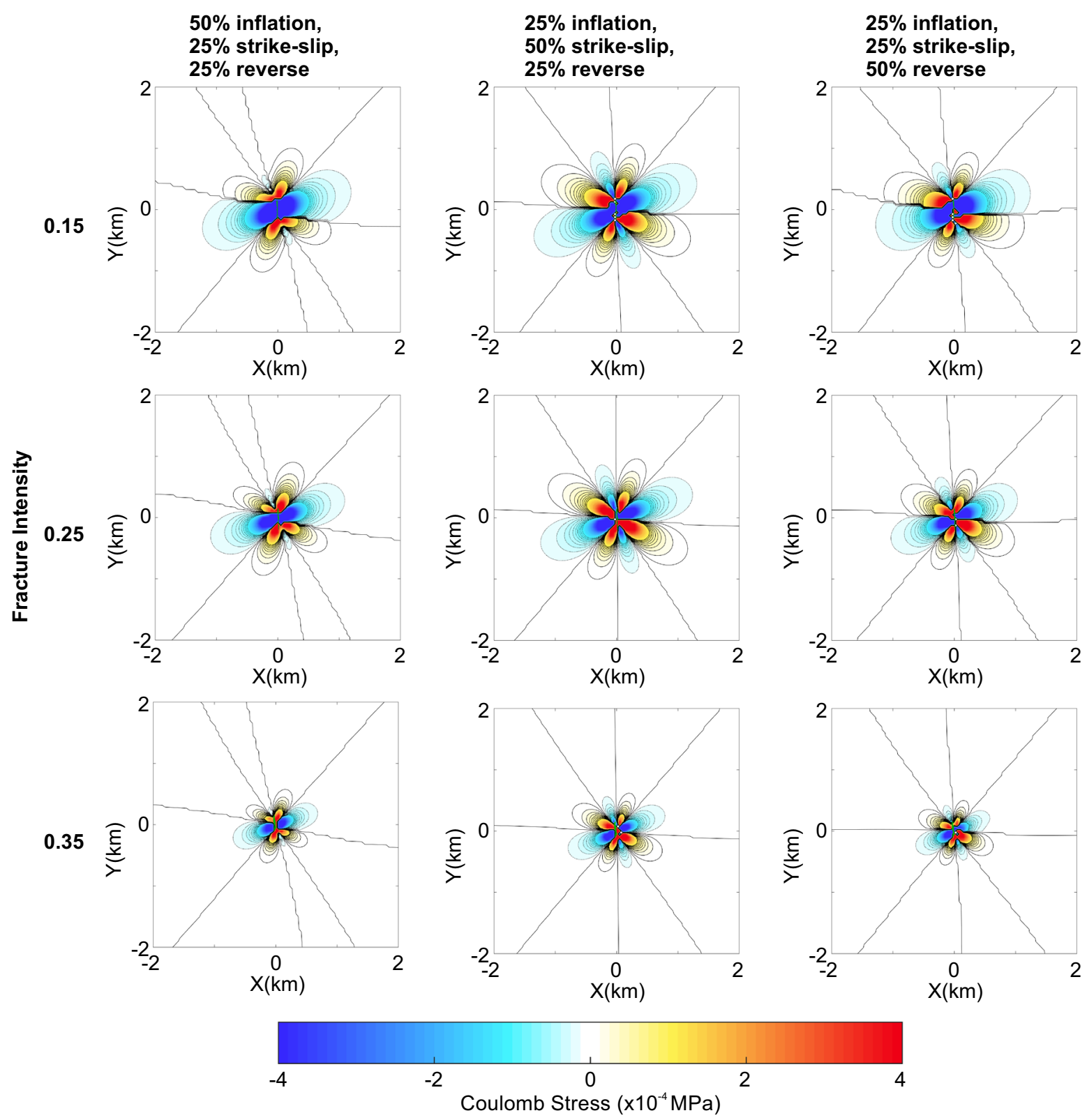

Fig. 5 Coulomb failure stress maps. The respective maximum and minimum stresses over depth is obtained and displayed in $2 \mathrm{D}$, with the fractures overlaid. The solid contour lines indicate the maximum strike-slip stress and the dotted contour lines the

expected as the higher stress changes will occur closer to the injection point and induced/reopened fractures. For the lowest stress threshold of $0.001 \mathrm{MPa}$, the worst case scenario would be that hydraulic fracturing would have to occur at least $433 \mathrm{~m}$ away from a minimum strike-slip stresses, both at $1 \mathrm{e}-5 \mathrm{MPa}$ intervals. The stress maps cover a $4 \mathrm{~km}$ square grid with $50 \mathrm{~m} \times 50 \mathrm{~m}$ cell sizes. The columns show the three different source mechanism weightings and the rows the three P32 fracture intensity values

critically stressed fault in order for it not to be reactivated by the Coulomb stress change. However, the results lie predominantly within $170-320 \mathrm{~m}$. Increasing fracture intensity, decreases the average value by $30-50 \mathrm{~m}$. The two source mechanisms 
Fig. 6 Two Coulomb failure stress maps generated from two of the 50 Monte Carlo simulations with the source mechanism $50 \%$ inflation, $25 \%$ strikeslip and $25 \%$ reverse
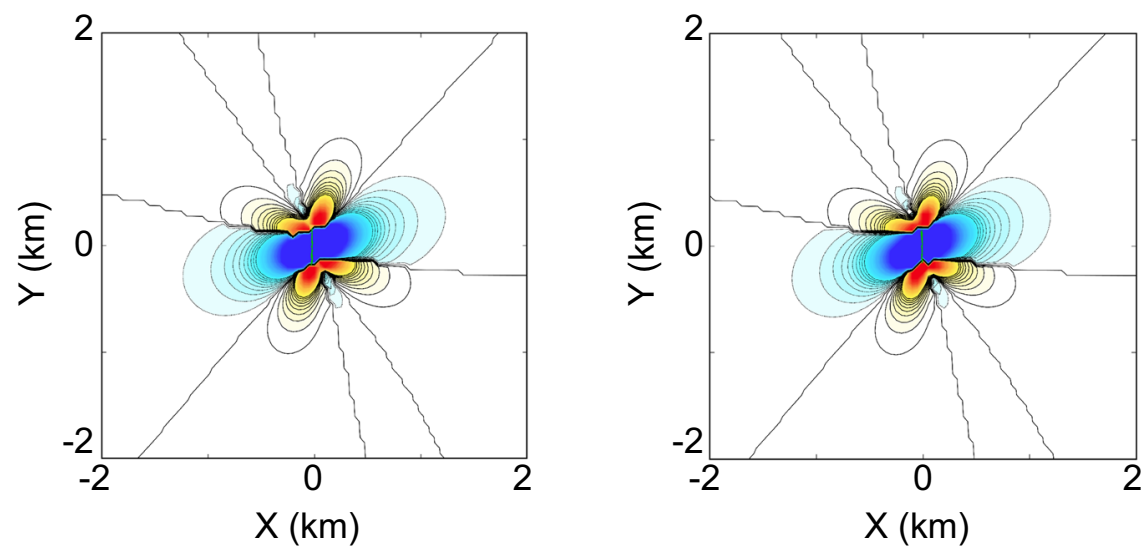

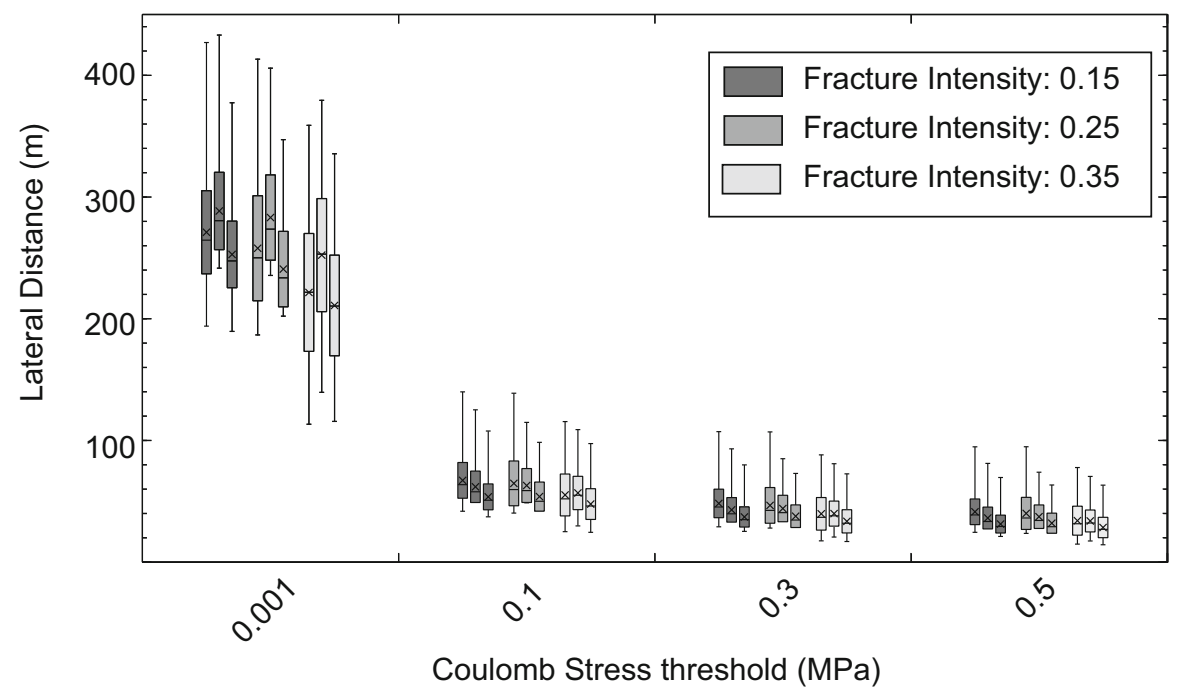

Fig. 7 The results relating to each stress threshold value [0.001 MPa (Kilb et al. 2002; Shapiro et al. 2006), 0.1 MPa (Stein 1999; Kilb et al. 2002; Freed 2005; Shapiro et al. 2006), $0.3 \mathrm{MPa}$ (Freed 2005) and 0.5 MPa (Kilb et al. 2002)] are calculated for the three P32 intensity values (shaded grey dark 0.15 , mid 0.25 and light 0.35 ) and three source mechanism

containing 50\% inflation and 50\% strike-slip produce a range of values larger than the $50 \%$ reverse mechanism. However, the majority of the results lie between + and - one standard deviation from the mean (the boxes in Fig. 7). This range is greatest for the $50 \%$ strike-slip mechanism by $20-50 \mathrm{~m}$.

For the higher stress values of $0.1,0.3$ and $0.5 \mathrm{MPa}$ the results lie predominantly between 20 and $80 \mathrm{~m}$ with the maximum lateral distance decreasing slightly with stress from 140 to $95 \mathrm{~m}$. Both the maximum and average lateral distances reduce with source mechanism in the order: 50\% inflation, 50\% strike-slip, 50\% weightings (from left to right $50 \%$ inflation, $25 \%$ strike-slip, $25 \%$ reverse; $25 \%$ inflation, $50 \%$ strike-slip, $25 \%$ reverse; $25 \%$ inflation, $25 \%$ strike-slip, $50 \%$ reverse). The tails indicate the maximum and minimum values of the data set, the box ends the mean plus/minus 1 standard deviation, the star is the mean and the horizontal line the median

reverse. However, the distance is small at less than $15 \mathrm{~m}$ from inflation to reverse for all three stress values.

To our knowledge, there is no literature available on the spacing of pre-existing faults in shale formations in the UK or America to be able to conclude what effect these distances have. However, in the UK, the Namurian Shales stratigraphically lie beneath the Westphalian Coal Measures (although not for the Bowland region, where the coal has been removed due to basin shortening, uplift and erosion). Any faults that are present in the Coal Measures of the Carboniferous 


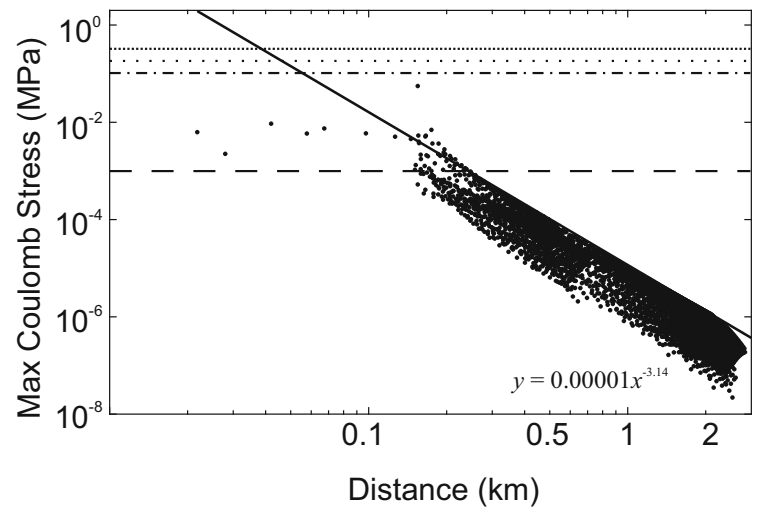

_ Shapiro et al. (2006) lower bound / Kilb et al. (2002) - lower bound

Stein (1999) / Freed (2005) lower bound / Shapiro et al (2006) upper bound / Kilb et al. (2002) optimal

..... Kilb et al. (2002) upper bound

Freed (2005) upper bound

Fig. 8 Maximum Coulomb stress versus distance for a P32 fracture intensity of 0.15 and source mechanism of $50 \%$ inflation, $25 \%$ strike-slip and $25 \%$ reverse. The horizontal lines are failure thresholds from Stein (1999), Kilb et al. (2002), Freed (2005) and Shapiro et al. (2006). The solid black line gives the maximum Coulomb Stress as a function of lateral distance (equation inset)

must also be in the shale. Considerable work has been conducted on the structure of these coals (e.g. Bailey et al. 2005; Walsh and Watterson 1988) and the spacing of the faults within them. One $400 \mathrm{~km}^{2}$ example in the East Pennine Coalfield contains 3030 faults (Bailey et al. 2005) (7.58 faults per $\mathrm{km}^{2}$ ) ranging from 10 to $16 \mathrm{~km}$ with throws of less than $180 \mathrm{~m}$. However, it is likely that not all of the faults would lead to a felt event.

3D seismic surveys can directly identify faults. Current technology is able to detect fault throws with a resolution of $5 \mathrm{~m}$ at best although more sophisticated processing can perhaps improve this (Zhou et al. 2015). General relationships between throw and fault length (Watterson et al. 1996) and between fault length and magnitude (Zoback and Gorelick 2012) of seismic events which occur on a fault suggest that a throw of $5 \mathrm{~m}$ would be from a fault of a few hundred metres in length and correspond to a seismic event of the order of ML 1.5, i.e. perceptible at surface in a quiet region by a general population. This is the magnitude of event which the traffic light system of Green et al. (2012) was designed to prevent and hence appears reasonably consistent with that intention. Much smaller faults will be present as part of the damage zone surrounding the main fault. However, while the number could be estimated from a power law distribution, with current technology it is unlikely that the presence could be determined. It is more sensible and realistic to identify a 'Master Fault', detectable on seismic reflection surveys, which can be considered to characterise the seismic potential of the region. This fault is likely to be up to $200 \mathrm{~m}$ in length with a $5 \mathrm{~m}$ throw and capable of generating a ML 1.5 seismic event.

Another consideration is the amount of stress which can cause a fault to move. Literature gives values ranging from 0.001 to $0.1 \mathrm{MPa}$. It is possible that all of these are correct depending on the exact nature of the fault, the fracture intensity and its closeness to criticality. The maximum respect distances then range from 63 to $433 \mathrm{~m}$, which is within the horizontal distance range (300-400 $\mathrm{m}$ ) that the reactivated fault was calculated to be from the injection point at Blackpool (Clarke et al. 2014).

It is also clear that fracture intensity plays a part and while it is not simple to assess the P32 (area of fractures per unit volume) intensity property directly, the P10 (number of fractures per unit length) values can be obtained from borehole derived fracture frequency (Rogers et al. 2015). This can be converted to a P32 intensity value using the borehole orientation, fracture orientations and dispersion (Wang 2005). Further modelling is recommended using borehole data once it is available, using the method described by Wang (2005) to constrain the fracture intensity value.

In 2014, the Ohio Department of Natural Resources issued new guidelines, which state that if permits for horizontal drilling are planned within 3 miles $(4.82 \mathrm{~km})$ of a known fault or area of historic seismicity (greater than ML 2.0), seismometers should be installed and if an event with magnitude greater than ML 1.0 occurs, activities should be paused. If this is found to be caused by hydraulic fracturing, then all well completion activities are suspended. Based on our results, these guidelines would cover the lateral distance over which the stress has an effect. However, this work has only focused on one set of pumping parameters and one geological setting from the UK and the results are likely to differ for other parameters and geology.

Our models were limited by data availability. Further modelling and reassessment is recommended 
once future wells are drilled and more detailed geomechanical and fracture data is available. These models are based on data obtained from the Blackpool, Lancashire, UK site and one set of pumping parameters and rock permeability. We suggest further sensitivity studies to investigate the effect that pumping parameters and geological scenarios have on the lateral respect distance. In addition, this model is limited by the exclusion of the poroelasticity effect. We recommend further work to include this effect which may increase the stress values and the respect distances provided in this paper. We also intend to further the work to investigate the effect that using a foam based fracturing fluid (Wanniarachchi et al. 2015; Lui et al. 2016) rather than a water based fluid have on the distances.

\section{Conclusions}

Using a Monte Carlo approach, we have created 3D discrete fracture network models for three P32 fracture intensities for a typical shale gas reservoir. We simulated a hydraulic stimulation stage at a depth of about $2220 \mathrm{~m}$ using pumping and geomechanical parameters based on the Bowland Shale. Calculation of the Coulomb stress change from the resultant hydraulic fracture networks showed only small differences between fracture intensities and source mechanism weightings. The results were compared to values in literature for the amount of stress change required to reactivate a fault close to failure. Modelling of the respect distance is not common and certainly not with respect to hydraulic fracturing operations. This is the first models to obtain possible values for the lateral respect distance using real-world inputs.

The following main results were obtained:

- The average maximum flow distance is close to uniform with values between 328 and $428 \mathrm{~m}$.

- The distance at which the stress change reduces to $0.001 \mathrm{MPa}$ increases with fracture intensity.

- The maximum horizontal respect distance varies from 63 to $433 \mathrm{~m}$, depending on fracture intensity and failure threshold value.

- There is less effect on the horizontal respect distance as the failure threshold value increases.

- The weighting of the source mechanism has little effect on the horizontal respect distance.
The maximum value of $433 \mathrm{~m}$ obtained using a $0.001 \mathrm{MPa}$ stress threshold and P32 value of 0.15 lies within the horizontal distance range from injection (300-400 m) of the reactivated fault which caused seismicity following hydraulic fracturing at Blackpool, Lancashire, UK (Clarke et al. 2014).

Acknowledgements This work was carried out as part of the ReFINE (Researching Fracking in Europe) consortium, which has been funded by Ineos, Shell, Chevron, Total, GDF Suez, Centrica and Natural Environment Research Council (UK). We thank the ReFINE Independent Science Board for prioritising the research projects undertaken by ReFINE. This work has also been supported by SHEER (SHale gas Exploration and Exploitation induced Risks), a project which has received funding from the European Union Horizon 2020 research and innovation programme under Grant Agreement No 640896. We thank Cuadrilla Resources Ltd. for providing geomechanical parameters and Mark Cottrell and Gareth Digges La Touche at Golder Associates (UK) Ltd for their support with FracMan ${ }^{\circledR}$. Thanks also goes to John Walsh of the Fault Analysis Group, UCD and Peter Hatherley at CSIRO for their valued advice and to the reviewers for their comments which have improved the manuscript.

Open Access This article is distributed under the terms of the Creative Commons Attribution 4.0 International License (http:// creativecommons.org/licenses/by/4.0/), which permits unrestricted use, distribution, and reproduction in any medium, provided you give appropriate credit to the original author(s) and the source, provide a link to the Creative Commons license, and indicate if changes were made.

\section{References}

Agarwal K, Mayerhofer MJ, Warpinski NR (2012) Impact of geomechanics on microseismicity. In: SPE/EAGE European unconventional resources conference and exhibition. Vienna, SPE 152835, pp 20-22. doi:10.2118/152835-MS

Atkinson G, Assatourians K, Cheadle B, Greig W (2015a) Ground motions from three recent earthquakes in Western Alberta and Northeastern British Columbia and their implications for induced-seismicity hazard in eastern regions. Seismol Res Lett 86(3):1022-1031. doi:10.1785/ 0220140195

Atkinson GM, Ghofrani H, Assatourians K (2015b) Impact of induced seismicity on the evaluation of seismic hazard: some preliminary considerations. Seismol Res Lett 86(3):1009-1021. doi:10.1785/0220140204

Bailey W, Walsh J, Manzocchi T (2005) Fault populations, strain distribution and basement fault reactivation in the East Pennines Coalfield, UK. J Struct Geol 27:913-928. doi:10.1016/j.jsg.2004.10.014

Baisch S, Vorös R (2011) Geomechanical study of Blackpool seismicity. Synthesis report. Report no.: CUA001

BC Oil and Gas Commission (2012) Investigation of observed seismicity in the Horn River Basin. BC Oil and Gas 
Commission, Victoria, BC. http://www.bcogc.ca/node/ 8046/download

BC Oil and Gas Commission (2014) Investigation of observed seismicity in the Montney trend. BC Oil and Gas Commission

Brady B, Brown E (1993) Rock mechanics for underground mining, 2nd edn. Chapman and Hall, London

Clarke H, Eisner L, Styles P, Turner P (2014) Felt seismicity associated with shale gas hydraulic fracturing: the first documented example in Europe. Geophys Res Lett 41(23):8308-8314. doi:10.1002/2014GL062047

Davies RJ, Mathias SA, Moss J, Hustoft S, Newport L (2012) Hydraulic fractures: How far can they go? Mar Petrol Geol 37(1):1-6. doi:10.1016/j.marpetgeo.2012.04.001

de Pater CJ, Baisch S (2011) Geomechanical study of Bowland Shale. Synthesis report, QCon

Dusseault MB (2013) Geomechanical aspects of shale gas development. In: Kwaśniewski M, Łydżba D (eds) Rock mechanics for resources, energy and environment. CRC Press, London, pp 39-56. doi:10.1201/b15683-7

Eisner L, Hallò M, Janskà E, Opršal I, Matoušek P, Clarke H, Turner P, Harper T, Styles P (2013) Lessons learned from hydraulic stimulation of the Bowland Shale. SEG Technical Program Expanded Abstracts, pp 4516-4520. doi:10. 1190/segam2013-0239.1

Ellsworth W (2013) Injection-induced earthquakes. Science 341:1225942. doi:10.1126/science. 1225942

Flewelling SA, Tymchak MP, Warpinski N (2013) Hydraulic fracture height limits and fault interactions in tight oil and gas formations. Geophys Res Lett 40:3602-3606. doi:10. 1002/grl.50707

Freed AM (2005) Earthquake triggering by static, dynamic, and postseismic stress transfer. Annu Rev Earth Planet Sci 33:335-367. doi:10.1146/annurev.earth.33.092203. 122505

Friberg PA, Besana-Ostman GM, Dricker I (2014) Characterization of an earthquake sequence triggered by hydraulic fracturing in Harrison County, Ohio. Seismol Res Lett 85:1295-1307. doi:10.1785/022014012

Gale JFW, Reed RM, Holder J (2007) Natural fractures in the Barnett Shale and their importance for hydraulic fracture treatments. AAPG Bull 91:603-622. doi:10.1306/ 11010606061

GMI Geomechanics Services (2011) Wellbore failure analysis and geomechanical modelling in the Bowland Shales, Blackpool, UK. Baker Hughes Incorporated, Subsurfac Integrity \& Evaluation

Golder Associates (UK) Ltd (2015) FracMan $^{\circledR}$ User's Manual Release 7.5 Reservoir Edition

Green CA, Styles P, Baptie BJ (2012) Preese Hall shale gas fracturing review \& recommendations for induced seismic mitigation. Independent report. https://www.gov.uk/ government/uploads/system/uploads/attachment_data/file/ 48330/5055-preese-hall-shale-gas-fracturing-review-andrecomm.pdf

Harper TR (2011) Well Preese Hall-1. The mechanism of induced seismicity. Geosphere Ltd

Hawkins AB, McConnell BJ (1992) Sensitivity of sandstone strength and deformability to changes in moisture content. Q J Eng Geol Hydrogeol 25(2):115-130. doi:10.1144/ GSL.QJEG.1992.025.02.05
Henderson P, Henderson GM (2009) The Cambridge handbook of earth science data. Cambridge University Press, Cambridge. ISBN 9780521693172

Hoek E (2007) Practical rock engineering. Rocscience. https:// www.rocscience.com/documents/hoek/corner/PracticalRock-Engineering-Full-Text.pdf

Holland AA (2013) Earthquakes triggered by hydraulic fracturing in south-central Oklahoma. Bull Seismol Soc Am 103:1784-1792. doi:10.1785/0120120109

Jaeger C (1972) Rock mechanics and engineering. Cambridge University Press, Cambridge. ISBN 052110338X

Keranen KM, Savage HM, Abers GA, Cochran ES (2013) Potentially induced earthquakes in Oklahoma, USA: links between wastewater injection and the $2011 \mathrm{Mw} 5.7$ earthquake sequence. Geology 41:699-702. doi:10.1130/ G34045.1

Keranen KM, Weingarten M, Abers GA, Bekins BA, Ge S (2014) Sharp increase in central Oklahoma seismicity since 2008 induced by massive wastewater injection. Science 345:448-451. doi:10.1126/science. 1255802

Kilb D, Gomberg J, Bodin P (2002) Aftershock triggering by complete Coulomb stress changes. J Geophys Res Solid Earth 107(B4):ESE 2-1-ESE 2-14. doi:10.1029/ 2001JB000202

Kim W-Y (2013) Induced seismicity associated with fluid injection into a deep well in Youngstown, Ohio. J Geophys Res Solid Earth 118:3506-3518. doi:10.1002/jgrb.50247

King GCP, Stein RS, Lin J (1994) Static stress changes and the triggering of earthquakes. Bull Seismol Soc Am 84(3):935-953

Lin J, Stein RS (2004) Stress triggering in thrust and subduction earthquakes and stress interaction between the southern San Andreas and nearby thrust and strike-slip faults. J Geophys Res Solid Earth 109(B2):B02303. doi:10.1029/ 2003JB002607

Lui HH, Ranjith PG, Georgi DT, Lai BT (2016) Some key technical issues in modelling of gas transport process in shales: a review. Geomech Geophys Geo-Energy GeoResour 2(4):231-243. doi:10.1007/s40948-016-0031-5

Maxwell S (2013) Unintentional seismicity induced by hydraulic fracturing. CSEG Rec 38(8):40-49

McGarr A, Bekins B, Burkardt N, Dewey J, Earle P, Ellsworth W, Ge S, Hickman S, Holland A, Majer E, Rubinstein J, Sheehan A (2015) Coping with earthquakes induced by fluid injection. Science 347(6224):830-831. doi:10.1126/ science.aaa0494

Okada Y (1992) Internal deformation due to shear and tensile faults in a half-space. Bull Seismol Soc Am 82(2):1018-1040

Rogers S, Elmo D, Webb G, Catalan A (2015) Volumetric fracture intensity measurement for improved rock mass characterisation and fragmentation assessment in block caving operations. Rock Mech Rock Eng 48:633-649. doi:10.1007/s00603-014-0592-y

Rutqvist J, Rinaldi AP, Cappa F, Moridis GJ (2013) Modeling of fault reactivation and induced seismicity during hydraulic fracturing of shale-gas reservoirs. J Pet Sci Eng 107:31-44. doi:10.1016/j.petrol.2013.04.023

Rutqvist J, Rinaldi AP, Cappa F, Moridis GJ (2015) Modeling of fault activation and seismicity by injection directly into a fault zone associated with hydraulic fracturing of shale-gas 
reservoirs. J Pet Sci Eng 127:377-386. doi:10.1016/j. petrol.2015.01.019

Schultz R, Stern V, Novakovic M, Atkinson G, Gu YJ (2015) Hydraulic fracturing and the Crooked Lake sequences: insights gleaned from regional seismic networks. Geophys Res Lett 42(18):2750-2758. doi:10.1002/2015GL063455

Shapiro SA, Kummerow J, Dinske C, Asch G, Rothert E, Erzinger J, Kümpel H-J, Kind R (2006) Fluid induced seismicity guided by a continental fault: injection experiment of 2004/2005 at the German Deep Drilling Site (KTB). Geophys Res Lett 33(1):L01309. doi:10.1029/ 2005GL024659

Skoumal RJ, Brudzinski MR, Currie BS (2015) Earthquakes induced by hydraulic fracturing in Poland Township, Ohio. Bull Seismol Soc Am 105(1):189-197. doi:10.1785/ 0120140168

Stein RS (1999) The role of stress transfer in earthquake occurrence. Nature 402(6762):605-609. doi:10.1038/ 45144

Sumy DF, Cochran ES, Keranen KM, Wei M, Abers GA (2014) Observations of static Coulomb stress triggering of the November 2011 M5.7 Oklahoma earthquake sequence. J Geophys Res Solid Earth 119(3):1904-1923. doi:10. 1002/2013JB010612

Toda S, Stein RS, Lin J (2011) Widespread seismicity excitation throughout central Japan following the $2011 \mathrm{M}=9.0$ Tohoku earthquake and its interpretation by Coulomb stress transfer. Geophys Res Lett 38(7):L00G03. doi:10. 1029/2011GL047834
Vasudevan K, Eaton DW (2011) Hydraulic fracturing: Coulomb failure stress in fracture networks. CSEG Rec 36:24-31

Verdon JP, Kendall J-M, Maxwell SC (2010) A comparison of passive seismic monitoring of fracture stimulation from water and $\mathrm{CO}_{2}$ injection. Geophysics 75(3):MA1-MA7. doi:10.1190/1.3377789

Walsh JJ, Watterson J (1988) Dips of normal faults in British Coal Measures and other sedimentary sequences. J Geol Soc Lond 145:859-873. doi:10.1144/gsjgs.145.5.0859

Wang X (2005) Stereological interpretation of rock fracture traces on borehole walls and other cylindrical surfaces. Ph.D. thesis, Virginia Polytechnic Institute and State University

Wanniarachchi WAM, Ranjith PJ, Perera MSA, Lashin A, Al Arifi N, Li JC (2015) Current opinions on foam-based hydro-fracturing in deep geological reservoirs. Geomech Geophys Geo-Energy Geo-Resour 1(3):121-134. doi:10. 1007/s40948-015-0015-x

Watterson J, Walsh JJ, Gillespie PA, Easton S (1996) Scaling systematics of fault sizes on a large-scale range fault map. J Struct Geol 18:199-214. doi:10.1016/S01918141(96)80045-9

Zhou B, Hatherly P, Sun W (2015) Enhancing fault detection by seismic diffraction imaging. Energy Flagship Report EP152277, CSIRO

Zoback MD, Gorelick SM (2012) Earthquake triggering and large-scale geologic storage of carbon dioxide. Proc Natl Acad Sci U.S.A. 109(26):10164-10168. doi:10.1073/pnas. 1202473109 